\title{
The Social Media Experiences of Long-term Patients: Illness, Identity, and Participation
}

\author{
Brita Ytre-Arne
}

\begin{abstract}
The present article investigates the meanings of social media use for long-term patients, focusing on a group of Norwegian bloggers diagnosed with myalgic encephalomyelitis (ME). This severe illness can confine patients to their homes for long periods of time, drastically reducing possibilities to participate on most social arenas and leaving Internet use as a rare opportunity for connection with the outside world. A qualitative analysis of interviews with ME bloggers investigates the meanings of social media use in this particular situation. Drawing on perspectives from research on patients' Internet use, this phenomenon is analysed as management of identity narratives in the face of illness. However, the article further argues that the concept of participation provides a relevant supplementary perspective that highlights the societal and political relevance of these practices.
\end{abstract}

Keywords: social media, participation, identity, narrative, illness, welfare state

\section{Introduction}

As the Internet has become an integral aspect of everyday life and contemporary society, an important orientation for media research is to explore the impact of the Internet on people's lives and in diverse societal contexts. These issues have been investigated using a myriad of theoretical perspectives, methodological approaches and empirical cases. Two important focal points are the issues of identity and participation. Studies have analysed how people express, construct and manage identities through Internet communication (Turkle 1995, Enli \& Thumin 2012, Rettberg 2014) and how they use the Internet to situate themselves within and participate in various communities, ranging from small social circles to political and public spheres (Baym 2010, Miller 2011, Moe 2011, Loader \& Mercea 2012). In particular, social media such as blogs and social network sites have been investigated as arenas for identity management and participation (Boyd 2014, Lövheim 2011, Enjolras et al. 2013, Fuchs 2014).

The present article contributes to these strands of research by analysing the social media experiences of a group of Internet users in a very particular situation, a situation that affects both conceptions of identity and possibilities for participation. This group consists of Norwegian bloggers who are also patients suffering from long-term myalgic encephalomyelitis (ME). This severe illness reduces patients' possibilities to engage in work, family activities and on social arenas outside the home. While ME is sometimes 
collapsed with Chronic Fatigue Syndrome (Grue 2013), severe fatigue is merely one of many symptoms that can leave ME patients housebound, bedridden and isolated for periods of time. Internet use thus emerges as a rare opportunity for connection between the patient and the outside world, and this particular context has implications for the meanings of ME patients' social media use.

Previous research has revealed high levels of social media engagement amongst Norwegian ME patients. A comparative study found higher levels of online forum activity for ME than other patient groups (Knudsen et al. 2012), and blogs by ME patients have appeared as central nodes in mappings of the Norwegian political blogosphere (Moe 2011). Popular histories of the Norwegian blogosphere have also noted the importance of ME blogging (Jackson 2010: 77, Westerby 2013). Furthermore, initiatives originating from ME patients through blogs and Internet forums have aimed to affect medical treatment, research funding and political attention concerning this disease (Westerby 2013: 186-190). Such use of social media by ME patients has been criticized (Bjerkestrand 2012) in debates that are part of broader discursive contestations concerning this illness. Ongoing struggles over the nature of $\mathrm{ME}$, treatment procedures and directions for research imply that patients find themselves at conflicting junctions in polarized debates (Jelstad 2012, Lian \& Bondevik 2013).

The present article analyses the meanings of social media use for ME patients, focusing on connections between the meanings of social media use in the lives of individuals and in society. The central method is qualitative interviews with Norwegian ME bloggers, but blogging is analysed in combination with other social media such as Facebook and Twitter. The theoretical perspective draws on previous research on patients' Internet communication, where theories about identity management in the face of illness have been important. However, while drawing relevant insights from this approach, the analysis will also highlight participation as a potential supplementary perspective. Through this analytical concept, identity negotiations in patients' social media use can be made relevant in the larger societal systems that surround them, thereby connecting the meanings of social media use in the lives of individuals to societal contexts. The analysis will start from the perspective of long-term patients and gradually broaden in focus to explore the participatory potentials of social media use.

\section{Research Perspectives on Patients' Internet Communication}

Patient's use of the Internet has been explored rather comprehensively, but reviews of the field emphasise that large bodies of research draw on relatively similar perspectives (Murero \& Rice 2006, Orgad 2005, Seale 2005). The Internet has transformed patients' opportunities to seek health information, potentially challenging the authority of the medical system and contributing to new forms of communication in patient groups and between patients and health care services (Tjora \& Sandaunet 2010). Shifting relations of power and knowledge have been important areas of research, focusing on e-health services, online support groups and most particularly information-seeking on the Internet (Nettleton et al. 2005, Kivits 2009, Mager 2009).

Sociologist Shani Orgad (2005) also highlights information-seeking and support communities in her review of research on patients' Internet communication, describing them as framed within a paradigm of conversational communication models (Orgad 2005: 30). 
She introduces the concept storytelling as an alternative for processes in which patients attempt "to produce a framework to organize disconnected elements into a whole and direct them towards closure" (Orgad 2005: 37). Storytelling stands in a dialectical relationship with agency, one prerequisite being the "ability to make sense of and construct a plausible story that can be incorporated into one's life" (2005: 41). Orgad draws on Anthony Giddens' (1991) sociological theory of agency and the role of narrative in the construction of the modern self. Giddens emphasizes reflexive dimensions of identity, understanding identity not as an essential inner truth, but as a narrative the individual strives to maintain through reflexive interaction with the world (1991: 14). Identity construction is complex and multi-layered, involving potentially conflicting conceptions.

While Orgad studied breast cancer patients, her concepts connect well with health sociology research on long-term or chronic illness. This has been understood as biographical disruption (Bury 1982), and the role of narrative as a structuring device for relating experiences of illness has been emphasized through categories such as restitution narratives, quest narratives and chaos narratives (Nettleton 2013: 74, Frank 1995). Looking at ME more specifically, studies have documented the complex social navigations patients experience as they try to make sense of their situation (Åsbring \& Närvänen 2002, Edwards et al. 2007). The theoretical concepts of Orgad and Giddens would thereby appear to be relevant to an analysis of ME bloggers' experiences, and the present article will start with identity and narrative as key concepts. Throughout the analysis, a supplementary perspective will be developed in order to also highlight how identity management connects to participatory dimensions of social media use.

\section{Methods: A Qualitative Study of Norwegian ME Bloggers}

The present analysis is based on qualitative interviews with a group of Norwegian bloggers suffering from ME. The purpose was to analyse the meanings of social media use in light of this particular situation, and a qualitative approach was chosen to allow for in-depth analysis of this phenomenon as situated in its context (Gentikow 2005, Gray 2003). Given the focus on social media use, the methodological approach needed to move beyond blog analysis and rather focus on bloggers' experiences. Qualitative interviews were chosen as a relevant method for such exploration.

The starting point for selecting informants was two blogs that had made notable contributions to the Norwegian blogosphere with regard to ME and other topics. These were Marias Metode ${ }^{l}$ by Maria Gjerpe, a doctor and ME patient who had participated extensively in public debate on health and welfare, and $\sim$ SerendipityCat $\sim^{2}$ by Catherine Eide Westerby, author of a long-running blog and a chapter on ME blogging in a history of the Norwegian blogosphere (Westerby 2013). Links and comments on these blogs were used to trace other ME blogs, and potential informants were selected based on the following criteria: 1) the blogger disclosed an ME diagnosis, 2) the blog was written by an adult, 3) the blog provided contact information, and 4) the blog addressed topics concerning the blogger's situation as a patient, such as reflections on life with illness, debates on ME or discussions of attitudes towards illness. Ten bloggers were invited to participate and eight interviews were eventually completed. ${ }^{3}$

Interviewing ME patients implies several ethical considerations, and by necessity, concerns owing to illness influenced certain methodological decisions. ${ }^{4}$ One problem 
was how to arrange comfortable interview situations for informants who might experience a face-to-face conversation as straining on their health. After being presented with many options, most informants agreed to be interviewed in written form through e-mail, one preferred Skype and one a mix of these methods. Importantly, all interviews were planned and carried out as qualitative interviews - the written interviews were not designed as questionnaires or surveys. Instead, an interview guide with questions in several parts was sent to informants with instructions that they could give as short or as long answers as they pleased and combine questions as they wished. Informants were given as much time as needed to reply, and all eventually answered the questions thoroughly. In some cases, follow-up rounds of questions and answers were conducted, and some also contributed additional information in later e-mails. In addition to meeting requirements mandated by informants' illness, use of written communication appeared to be well suited to their experiences as bloggers. The Skype interviews followed the same interview guide and were transcribed in full for analysis. ${ }^{5}$

The interviews focused on blogging as part of a broader spectrum of social media activity, including for instance Facebook and Twitter. All interviews covered topics such as blog history, use of different social media, Internet use in everyday life, and social media in relation to ME. The interviews were analysed thematically, starting from a hypothesis building on the analytical perspective outlined above: that ME bloggers' social media use is made meaningful as a way of reconstructing identity narratives when faced with long-term illness. The analysis therefore begins by exploring social media use in relation to the particular situation of ME patients before moving on to their participation in different communities.

\section{Analysis of ME Patients' Social Media Use}

\section{Managing Narratives of Illness and Identity}

Why would an ME patient start a blog? The answer most informants gave was that they had heard of someone who was blogging and thought that this was something they could try - for various reasons. Some told stories of "coming back" from periods of severe illness and wanting to catch up with technological developments, while others thought that blogging would be a practical way of updating friends and family. On a deeper level, blogging appeared to respond to a need caused by the situation of being ill:

When I started blogging I was bedridden without possibilities for social contact or arenas to be on. I ate alone. Had twelve hours each day with minimal contact with other people. A lot of my time was spent just lying down, without being online, without reading, just letting my thoughts wander. Then those thoughts become something that wants to find an expression, and often I wrote blog posts in my head while lying there waiting to be able to sit back up. Now I live a social life with my family, with friends and I even leave the house. There is no longer time to write long texts or think long thoughts in the same way as before. After 18 months of almost complete isolation and silence I had a great need to not contemplate, to keep the silence away. Now perhaps the need is starting to make itself known again, and who knows what I might want to share of my thoughts? - Beate ${ }^{6}$ 
I started blogging to express what was pressing on me from within; I needed an outlet for what was moving inside me. At the same time, I needed to not feel empty and to escape the sense of waiting. I don't think life can be put on hold and continued later. Life is all the time. I had an idea that my life would not have a big void there, but that the time with ME would be filled with something that can be used on a résumé at a later date. I would use my time on something that made sense to me, have an alternative outlook on life - since it could not be lived as I had expected. While restrictions on life were considerable, a room for selfrealization opened up. - Anne-Helene ${ }^{7}$

Both quotes point to a need for meaning-making through creative expression. Blogging is described as a pressure-relieving outlet, made necessary by an illness that confines patients to their homes and to their own minds. Blogging is portrayed as a way of making time with illness more meaningful, and making meaning of a difficult situation.

The theoretical perspective Orgad outlines, referring to Giddens, offers relevant insights for understanding these experiences. Giddens' concept reflexive identities (1991) illuminates the ways in which ME bloggers were forced to rethink their sense of self when faced with fundamental disruptions in their lives. In the second quote, the informant describes her need to develop alternative conceptions of what constitutes a meaningful life. ME can be understood as a life crisis, affecting multiple aspects of everyday life and calling into question life plans and conceptions of identity. An ME diagnosis can imply brutal confrontations with questions such as "what is my place in society when I am unable to work?" or "how can I best be a parent when I cannot be with my children outside the home?" Patients might find themselves forced to rethink their sense of self without drawing on established social roles. This poses a difficult challenge to the task of keeping a coherent identity narrative together, as multiple dimensions of the self are challenged simultaneously and dramatically, while outcomes are left uncertain.

Orgad's concept of storytelling as "the attempt to produce a framework to organize disconnected elements into a whole and direct them towards closure" (2005: 37) also appears relevant, but the notion of closure is problematic to transfer to ME patients, as there is no definite treatment or timeframe of recovery. Similarly, a study of patients with unexplained neurological symptoms found that their experiences came closer to socalled chaos narratives than the more culturally legitimate restitution narratives in which the patient moves towards recovery (Nettleton 2013: 76). The first informant quoted above had experienced significant improvement and was able to construct a restitution narrative, while the second informant focuses on the process of rethinking narratives. Importantly, difficulties in formulating clear-cut narratives only strengthen the relevance of understanding ME blogging as a way of managing such identity narratives.

In both quotes, positioning of the self in social contexts is crucial, as the informants speak about identity management. The first informant describes the loss of ordinary social contact as the direct reason for making meaning through blogging, using the phrase "without arenas to be on" to depict her previous situation. The second describes blogging as a way of building personal competence in order to participate in the workforce again in the future. Both accounts emphasize social media use as ways of coping with reduced possibilities for participation. As well as exploring participatory dimensions further, it is necessary to ask why social media would be preferable outlets for these processes. 


\section{Participation in Social Circles: Controlled Communication}

When informants described their social media use, they emphasized that certain capacities of Internet communication were adjustable to their needs as ME patients. Social media use could not fully replace - but could partly supplement - a little of what they were missing in terms of participation on other social arenas, such as circles of acquaintances and friends:

The Internet is nice in that way, as I can control how available I am. It doesn't require as much of me as meeting someone in person would. On bad days, the Internet is all I can take. I guess this is why ME patients are accused of being overrepresented online. In a way I feel that I've become weird and withdrawn since I became ill, but I do find that every time I have a good period I'm more out and about and less online. - Lothiane ${ }^{8}$

Communication with people I know in physical life can sometimes be demanding because it builds on information we already have about each other. It's difficult for a 'ME head' to keep track of a lot of information at the same time, which is needed to keep up a fluent and meaningful conversation. Communication with Net acquaintances is low-threshold, expectations are loose and how I'm seen is how I represent myself. That can be liberating, especially when my cognitive levels are low due to exhaustion. - Anne-Helene

Here, Internet communication is perceived as limited compared to the richness of faceto-face interaction, but these limitations enable manageability and thereby control. Related discursive themes explain how the idea of controlled communication is constructed: a notion of written language as precise, peeling away interesting but disturbing layers of social meaning, and social acceptance of delay - the ability to wait and shield oneself. With this view of the possibilities of Internet communication, many informants moved from blogging to also testing other social media. In this process, they evaluated how their own abilities as ME patients worked with the capacities of different social media:

I've been on Twitter, but it's too fast. It's so fast, and you need to be alert. I have an account, and a couple of years ago I ended up in a discussion with some doctors, and there was a lot of resistance and a sharp tone, and I felt that this was something I couldn't control. I was not ready and alert enough to stick to the case and keep track, so I chose to drop it. And there is too much going on there. I've decided not to use my energy there. [...] [Facebook] is slower. [Laughter] [...] Facebook might be a little slow, but it's safe and you can say things very briefly. Two lines about something are enough. That's good. - Fremad $i$ alle retninger

I feel insufficient... in the sense that I cannot use [Twitter] as I would like. When I'm cognitively impaired I'm unable to think as quickly as I used to. Participating in debates is practically impossible because I can't keep track of my own arguments, let alone others'. It's quite simply not possible to discuss things on a reasonable level. I'm left short due to my illness. - Lokki ${ }^{9}$

An important aspect here is the communicative spheres that informants envision themselves entering through different social media. Twitter is described as a public sphere for rational deliberation, while Facebook is understood as mirroring communities in one's 
personal life. While some wanted to participate in the public sphere through social media use, others emphasized personal support in smaller social circles. These informants described Twitter as having a pace and form that established requirements they could not meet, while Facebook was safer, slower and friendlier. They referred to social and cultural conventions for use, as mere technological features would render Twitter's character limit better suited than Facebook to their desire for brevity. Facebook was, however, the most important social medium for most informants. The diverse uses of this popular service could easily be appropriated to their different needs, keeping in touch with friends outside the sphere of illness but also taking part in closed or open ME groups. Some described ME blogging as a phenomenon of the past, while Facebook had emerged as the crucial arena for continuing communication that had previously been established through blogging.

\section{Participation in Patient Communities: Ambivalences and Dilemmas}

There was considerable variation in how informants connected social media use to illness, and this too varied over time. The possibility to communicate with fellow patients through social media was appreciated, but found different expressions:

It's nice to get support. It's often the same people reading my posts and commenting, and I comment on their blogs. That becomes a small community. You update each other and ... care about each other, actually. If someone hasn't been blogging for a while, you might e-mail and ask how it's going. Is it quiet because things are good, or because things are bad? There's a lot of caring in that - Fremad $i$ alle retninger

Social media have been, and are, an invaluable tool for ME patients worldwide, so that they can come together and work together, share information and experiences. Before the Internet, people would lie at home suffering in silence, and that could probably explain why there was a high suicide rate amongst patients. Now you are actually not alone anymore, you get to know that there is research going on in Australia or in the US that you might recognize yourself in... that gives hope. It seems like something is happening now, and hopefully we are approaching better diagnosis and treatment options - Lothiane

Here, the first informant speaks of support and care being exchanged when social media communication overlaps with interpersonal communication, while the second refers to an international community with a common cause. She gives a forceful account of how Internet use gives housebound patients access to knowledge, community and voice, enabling participation in a patient community where empowerment and agency are central elements. However, ideas about being a "ME blogger" or taking part in a patient community were also troubling to some. An example is this response to a question about the environment ${ }^{10}$ of ME blogging:

I don't feel the need to be part of an environment, but I'm interested in individuals. I don't know what the so-called ME environment is, or who's included in it. When I communicate with people, whether they have ME or not, it's dialogue and interaction that matters the most. When I write about life with ME, I'm most likely to encounter people who have the disease or have close relations who do. 
These people are still primarily individuals to me. I don't know who belongs to this or that environment, nor do I know how many environments there are. As I said before I don't engage in other people's conflicts and consequently I don't have insight into them and so I don't know what a possible ME environment consists of. The most important thing is to relate to and communicate with people one feels on the same level as and where dialogue is characterized by mutual respect. - Anne-Helene

Here, respectful dialogue is contrasted with the idea of an environment of ME bloggers. One probable explanation is the highly polarized debate on ME in Norway, a debate most informants wanted to avoid. They felt estranged from common discursive constructs of what "ME patients" were like, and while debate participation could nuance such constructs, they also risked being taken as representatives of the labels they sought to escape. A strategy for handling this dilemma was to emphasize that they blogged about personal experiences and "their own story".

As Orgad argues, experienced patients might teach the newly diagnosed not just about the illness, but also about discursive conventions of communicating about illness online (2005: 123). Some ME bloggers who had been ill for years had also been early adopters of social media, resulting in considerable expertise in Internet communication on health and illness. They balanced feelings of obligation to help the newly diagnosed they encountered online with feelings of tiredness over the endless circles of debate on ME. When necessary they would give newcomers advice on how to find information and community through social media, but also on how to avoid further conflict and stigmatization of the patient group.

\section{Participation in the Public Debate: Contributing through Experience}

The dilemmas described above indicate that participation in patient communities is closely integrated with societal discourses on health and illness. The position of the patient in the health system is a lived reality for those concerned, but also a topic of debate in the public sphere. Both users and non-users of health and welfare services can participate in such debates with reference to their shared roles as members of publics, citizens of the state, media audiences or users of social media. Some ME bloggers sought to communicate their particular experiences as direct contributions to public debates on the politics of health and welfare. In contrast to discussion forums or Facebook groups that could be closed to outsiders, the open blog medium could imply orientations towards a broader public:

I started blogging as an attempt to render illness harmless, maybe primarily for myself, but also with a hope of giving insight and understanding of what it's like to stand on the outside of life, not being able to participate. There is a form of therapy in writing, and I don't share everything I write, but it's a way to breathe. By blogging from my perspective, I hope to get those who are healthy out there in life to stop for a moment and appreciate what they've got. That's important. - N.N. ${ }^{11}$

It's surprised me how many people I've gotten to know through social media. How easy it is to participate even though I can't participate in real life. It's my social arena. That's also why it's important to me. I would not have been this active in 
social media if I hadn't been ill. [...] It's my way of showing that I exist, that I still have something to contribute - N.N.

Both quotes are from the same informant, who starts by describing blogging as personal meaning-making, but goes on to envision a message to the public. She uses metaphors of location when she situates herself as trapped in a sphere of illness, and by blogging she reaches into "life", trying to capture people's attention. Emphasizing social media as a rare connection between the housebound patient and the outside world, she uses this connection to carve out a place for herself on a broader social arena. Social media are the arena where she can participate and be recognized as a contributing member of society, sharing experiences of what it is like to live with long-term illness in the Norwegian welfare society.

Such use of social media ties to discussions on whether patients' Internet communication makes visible previously neglected experiences, integrating them into the public realm (Harrison 2014, Orgad 2007). In her research on breast cancer patients' online communication, Orgad has argued that this is generally not the case, due to "a combination of disembodied, anonymous, patients-only and highly personalized space and discourse" (Orgad 2007:156). While the same could be said of some aspects of ME patients' social media use, parts of their Internet communication were not patients-only, not personalized in discourse, and not anonymous. Some blogged about problematic encounters with the health services, bureaucratic struggles to get assistance or entitlements, or reactions to political debates on the organization of welfare services. Initiatives originating from $\mathrm{ME}$ blogs have received political attention and resulted in meetings with health ministers and other authorities, thereby contributing to visibility in the public realm (Westerby 2013). Blog posts written by ME bloggers have also been republished as debate pieces in widely read news media. Last but not least, a particular event in 2013 provided a striking example of social media use as patient activism.

\section{Participation as Patient Activism: From Debate to Action}

In the spring of 2013, a Norwegian foundation called MEandYou collected nearly three million Norwegian kroner in a crowdfunding campaign. Crowdfunding is often associated with the creative arts, but this campaign aimed to fund a medical research project testing a new drug treatment for ME. Doctors Olav Mella and Øystein Fluge at Haukeland University Hospital in Norway had discovered improvement in ME patients treated with the cancer drug Rituximab, and after conducting pilot studies they applied for funding for a larger clinical trial. In December 2012, the Research Council of Norway announced its annual endowments for independent projects, but the Rituximab study was unsuccessful despite receiving a good evaluation.

Several ME patients expressed their disappointment in blogs and on Twitter and Facebook, but blogger Maria Gjerpe declared that despair should be turned to constructive action. ${ }^{12}$ She established MEandYou as a crowdfunding initiative, the aim being for patients to fund the research themselves. Gjerpe was an ME patient, a doctor and an experienced blogger who had participated in media debates on health, communication and welfare. Her blog had also won a grant from the Norwegian Freedom of Expression Foundation for its contributions to public debate. As opposed to most informants in this study, she had from early on thought of her blogging as an address to a public sphere: 
I started blogging to systematize my search for treatment. After two blog posts I understood that Maria's Metode dealt with topics concerning communication and doctor-patient relationships, and that it could not be a diary blog. [...] Eventually I became an active participant in the public debate, both with blog posts, interviews and writing in newspapers - Maria ${ }^{13}$

Gjerpe was a pilot patient for Rituximab treatment, and after the Research Council's decision she devoted her renewed energy to fund further research on the medicine that had helped her. As her improvement was expected to be temporary, she set up MEandYou as a campaign that would last 90 days and within this timeframe collect 7 million NOK. This ambitious goal was not achieved, but the foundation made a significant contribution and attracted considerable attention from politicians, contributors and news media. The proclaimed close of the MEandYou campaign in June 2013 concurred with the news that the Research Council would fund the Rituximab study after all, and the Minister of Health approvingly tweeted that further ME research should be a priority.

MEandYou inspires questions about the role of patients in the health care system and about public opinion and how it can be influenced. Intersecting with these questions, the campaign highlights the potential of social media as an arena for mobilization. Social media were crucial for a number of reasons. The first was Gjerpe's blog and the position she had built through it, establishing herself as credible and resourceful in patient communities and in the public debate. The blog was also an effective outlet for sharing her story of improved health and her quest to help others. A second reason was the active use of Twitter, Facebook, YouTube and other social media to share campaign information, and a variety of bloggers with and without experiences of ME promoted MEandYou. The third reason was a campaign rhetoric that drew on narrative devices with mobilizing force, such as Gjerpe's quest and the hopes for a medical breakthrough, visuals and videos for sharing across social media, and slogans such as "Sharing is caring" and "Let's walk together", emphasizing community, empowerment and participatory culture.

The MEandYou campaign constitutes a special case, but it nevertheless gives an example of the participatory potential of social media use in a patient group. The initiative could be seen as patient activism - here understood as organized public action in the pursuit of defined goals that affect the prospects of a patient group - carried out with social media as the central arena. The notion of patient activism carries with it some tension due to the critique of ME bloggers, but has at times been used by bloggers themselves (Westerby 2013). The role of the patient activist refers to and challenges ideas of what it means to be a patient in the health care system, actively seeking to address power balances and influence decisions. This case, where social media were crucial in transforming patients into activists, illustrates the relevance of further research into how social media are used for mobilization and public engagement by a wide array of social groups in different societal systems.

\section{Social Media and Participation in the Welfare State}

Meanings of social media use for long-term patients could span from management of personal identity narratives through participation in different communities to political patient activism. A contextualized conceptualization of participation could further illuminate how these dimensions are connected. 
Participation is an important concept in democratic theory and widely used in different strands of research (e.g., Pateman 1970, Held 1996). In media research, recent works have highlighted participation as an analytical concept used in analysis of audience transformations (Carpentier \& Dahlgren 2014). Participation can be defined as referring to "questions of citizen's inclusion in the dynamics of decision-making" (Carpentier et al. 2013: 123). Foundations for participation can encompass structural opportunities concerning institutional mechanisms of inclusion and exclusion, cultural resources that might be unevenly distributed amongst groups, and subjective dispositions formed in cultural and structural contexts, but on an individual level (Carpentier et al. 2013: 125). This conceptualization privileges an underlying view of participation in terms of connections between individuals and societal systems, referring to the existence of multiple actors with power positions, situated in a context (Carpentier 2013: 125). In order to address specific modes of participation, it is thus necessary to consider which context one envisions participation taking place in.

Research on participation often investigates citizens' possibilities to take part in political processes, exemplified by Carole Pateman's classic work on participatory democracy (1970). Participation, however, can be conceptualized without reference to the formal political system, as the notion of actors aiming to affect power balances can be transferred to other societal systems. For the purpose of analysing patients' participation, the health care sector is an obvious example, but in countries such as Norway health care is part of broader welfare systems. In the Nordic countries, the welfare state is a societal system of great significance in people's lives, in the constitution of social groups, and in the political debate and state organization (Hatland et al. 2011). Patients encounter this system when they seek treatment, but also entitlements or assistance when they are unable to work, or when facing different everyday challenges resulting from illness. Patients and welfare users are also citizens of a state where welfare is a central policy domain and an important topic in the public debate (Hatland 2011). The welfare state can thus be viewed as a complex and multifaceted social system where political and personal discourses blur the public-private divide, and where different modes of participation might be envisioned.

One mode of participation in the politics of the welfare state refers to the ways in which users of welfare services - e.g. patients in the health care system - voice concerns and attempt to influence their own situation, drawing on subjective dispositions and shared cultural resources. A different mode of participation refers to the ways in which citizens - both users and non-users of welfare services - take part in political processes and public debates on legitimization, organization and challenges in the welfare state. As indicated by the experiences of ME bloggers, social media use could be relevant to both modes of participation. Through social media use, long-term patients can participate in the welfare state through patient communities or patient activism, but also as citizens making contributions to public debates on different dimensions of the welfare state.

\section{Conclusion: Connecting Identity and Participation in Social Media Use}

The present analysis has explored the social media experiences of long-term patients, focusing on meanings of social media use in the lives of individuals and in society. Participatory dimensions of media use have been highlighted by gradually expanding the 
analytical focus from the situation of the isolated long-term patient to the communities and publics he or she can enter through social media use. In so doing, the focus has also shifted from questions of identity management to questions of participation. As mentioned in the introduction, identity and participation are focal points in media research exploring the significance of the Internet in life in contemporary society. A relevant question is, therefore, what this particular case signals regarding how these dimensions can be connected - empirically, theoretically and methodologically.

The empirical findings of the present analysis indicate that participatory dimensions of long-term patients' social media use are closely intertwined with personal aspects of managing identity in the face of severe illness. A patient's process of rethinking the self is not merely relevant to the individual, it also refers to and potentially challenges dominant discourses of what it means to participate in society: Which social arenas matter, how and why? Which forms of participation are relevant? What are the implications of health and illness for inclusion and exclusion in a welfare society? Social media offer communicative tools for addressing these matters, and for sharing reflections on them. In other words, identity management through social media can be understood as a personal and cultural resource for participation in important public conversations.

Theoretically, connections between identity and participation can be highlighted by employing perspectives with a broad view on how media use is made relevant in society. As indicated by the present analysis, some established concepts in research on patients' Internet use build on theories that facilitate such connections. An example is Orgad's (2005) conceptualization of storytelling, which draws on Giddens' theory of the reflexive self - a theory that situates narrative identity work in societal contexts. This can further be connected to conceptualizations of participation where cultural resources and subjective dispositions are counted as important foundations (Carpentier et al. 2013), and where modes of participation beyond the formal political system are included.

Another insight, highlighted by employing interview methods, is the importance of investigating the shifting meanings of social media use over time. Such shifts are not necessarily expressed in the texts of social media, but could be experienced and accounted for by users. As exemplified by this case, long-term patients' social media use can initially find importance as identity management and small-circle sharing of support. However, by ensuring continued inclusion in communities, latent potentials for changing modes of participation are continued and can eventually take on different meanings. This may lead to surprising outcomes, such as patient activists mobilizing for the MEandYou campaign - an initiative that moved beyond the personal to directly address power relations in the systems of medical research, health care and the welfare state. For media research on the diverse meanings of social media use, this illustrates that not merely participation, but also potentials for participation constitute a relevant research orientation.

\section{Notes}

1. http://mariasmetode.no/

2. www.serendipitycat.no/

3. Of the two blogs that served as starting points, Gjerpe was interviewed while Westerby referred to her book chapter. While thematically relevant, this is not counted as an interview.

4. The collection and management of data were approved by the Norwegian Data Protection Official for Research and carried out in compliance with regulations. 
5. Informants were asked whether they preferred being quoted anonymously, or identified as they are on their blogs (by 'nickname', given name, full name, and/or blog name). Identification will vary according to their choices.

6. Beate, author of http://Beatesrasteplass.wordpress.com E-mail interview, also interviewed on Skype.

7. Anne-Helene Ose-Johansen, author of http://Melivetpaaslep.wordpress.com E-mail interview.

8. Lothiane (nickname). E-mail interview.

9. Lokki (nickname), author of http://levlivetlett.se E-mail interview.

10. The Norwegian word 'miljø' translates to environment, and can be used to refer to loose social and cultural groupings (e.g., 'the student environment').

11. E-mail interview with anonymous informant.

12. Marias Metode (5.12.2012): http://mariasmetode.no/2012/12/forskningsradet-har-avslatt-soknaden-visamler-inn-selv-funding-rejected-patientdriven-foundation/

13. Maria Gjerpe, author of http://mariasmetode.no/

\section{References}

Bjerkestrand, Stine (2012) "Maktskiftet [Power Change]". Tidsskrift for Den norske legeforening [The Journal of the Norwegian Medical Association] 24(2): 125-132.

Baym, Nancy (2010) Personal Connections in the Digital Age. Cambridge: Polity.

Boyd, Danah (2014) It's Complicated. The social lives of networked teens. New Haven: Yale University Press. Bury, Michael (1982) "Chronic Illness as biographical disruption”. Sociology of Health and Illness 4 (2): 167-182.

Carpentier, Nico, Dahlgren, Peter \& Pasquali, Francesca (2013) “The Democratic (Media) Revolution: A Parallel Genealogy of Political and Media Participation”, pp. 123-41 in Carpentier, Nico, Schrøder, Kim \& Hallett, Lawrie (eds.) Audience Transformations. Shifting Audience Positions in Late Modernity. New York: Routledge.

Carpentier, Nico \& Dahlgren, Peter (2014) "Histories of media(ted) participation: An introduction". CM: Communication Management Quarterly 30: 7-14.

Edwards, Catherine, Thompson, Andrew, \& Blair, Alan (2007) “An 'Overwhelming Illness': Women's experiences of Learning to Live with Chronic Fatigue Syndrome/ Myalgic Encephalomyelitis”. Journal of Health Psychology 12(2): 203-14.

Enjolras, Bernard, Karlsen, Rune, Steen-Johnsen, Kari \& Dag Wollebæk (2013) Liker, liker ikke. Sosiale medier, samfunnsengasjement og offentlighet [Social media, societal engagement and public sphere]. Oslo: Cappelen Damm.

Enli, Gunn \& Thumin, Nancy (2012) "Socializing and Self-Representation online: Exploring Facebook". Observatorio (OBS*) 6(1): 87-105.

Frank, Arthur (1995) The Wounded Storyteller: Body, Illness and Ethics. Chicago: University of Chicago Press.

Fuchs, Christian (2014) Social media: A critical introduction. London: Sage.

Gentikow, Barbara (2005) Hvordan utforsker man medieerfaringer? Kvalitativ metode [How to explore media experiences? Qualitative methods]Kristiansand: IJ-forlaget.

Giddens, Anthony (1991) Modernity and Self-Identity. Self and Society in the Late Modern Age. Cambridge: Polity.

Gray, Ann (2003) Research Practice for Cultural Studies. London: Sage.

Grue, Jan (2013) “A garden of forking paths: a discourse perspective on 'myalgic encephalomyelitis' and 'chronic fatigue syndrome'." Critical Discourse Studies, online publication.

Harrison, Katherine (2014) "Online negotiations of infertility: Knowledge production in (in)fertility blogs." Convergence 20(3): 227-351.

Hatland Aksel, Kuhnle, Stein \& Romøren, Tor (eds.) (2011) Den norske velferdsstaten [The Norwegian Welfare State]. Oslo: Gyldendal.

Held, David (1996) Models of Democracy. Cambridge: Polity.

Jackson, Ida (2010) Sosiale medier. Hvordan ta over verden uten å gå ut av huset [Social media. How to take over the world without leaving your house]. Oslo: Aschehoug.

Jelstad, Jørgen (2011) De bortgjemte - og hvordan ME ble vår tids mest omstridte sykdom [The hidden - and how ME became the most controversial disease of our time]. Oslo: Cappelen Damm.

Kivits, Joëlle (2009) "Everyday health and the internet: a mediated health perspective on 'health information seeking". Sociology of Health \& Illness 31(5): 673-87.

Knudsen AK, Lervik LV, Harvey SB, Løvvik CMS, Omenås AN and Mykletun A (2012) "Comparison of chronic fatigue syndrome/ myalgic encephalopathy with other disorders: an observational study". JRSM Short Reports 3:32. 
Loader, Brian D. \& Dan Mercea (eds.) (2012) Social Media and Democracy. Innovations in participatory politics. London: Routledge.

Lövheim, Mia (2011) "Personal and Popular. The Case of Young Swedish Female Top- bloggers", Nordicom Review 32(1): 3-16.

Mager, Anne (2009) "Mediated health: sociotechnical practices of providing and using online health information". New Media \& Society 11(7): 1123-1142.

Miller, Daniel (2011) Tales from Facebook. Cambridge: Polity Press.

Moe, Hallvard (2011) "Mapping the Norwegian Blogosphere: Methodological Challenges in Internationalizing Internet Research”. Social Science Computer Review 29(3): 313- 26.

Murero, Monica \& Rice, Ronald (eds.) (2006) The Internet and Health Care. Theory, Research, Practice. New York: Routledge.

Nettleton, Sarah (2013) The Sociology of Health and Illness. Cambridge: Polity.

Nettleton Sarah, Burrows, Roger \& O'Malley, Lisa (2005) “The mundane realities of the everyday lay use of the internet for health, and their consequences for media convergence". Sociology of Health \& Illness 27(7): 972-92.

Orgad, Shani (2005) Storytelling Online. Talking Breast Cancer on the Internet. New York: Peter Lang.

Orgad, Shani (2007) "The Transformative Potential of Online Communication", Feminist Media Studies 5(2): 141-161.

Pateman, Carole (1970) Participation and Democratic Theory. Cambridge: Cambridge University Press.

Rettberg, Jill (2014) Seeing Ourselves Through Technology. Basingstoke: Palgrave Macmillan.

Seale, Clive (2005) "New directions for critical internet health studies: representing cancer experience on the web". Sociology of Health and Illness 27(4): 515-540.

Tjora, Aksel \& Sandaune, Anne-Grete (2010) Digitale Pasienter [Digital Patients]. Oslo: Gyldendal.

Turkle, Sherry (1995) Life on the Screen. Identity in the Age of the Internet. New York: Simon \& Schuster.

Westerby Catherine (2013) "Pasientaktivist på sengekanten [Bedside Patient Activist]”, pp. 165-202 in Bjørkelo, Kristian (ed.) Gi meg en scene! Norsk blogghistorie [Give me a stage! Norwegian blog history]. Oslo: Humanist forlag.

Åsbring, Pia \& Närvänen, Anna-Lisa (2002) Women's Experiences of Stigma in Relation to Chronic Fatigue Syndrome and Fibromyaliga. Qualitative Health Research 12(2): 148-60.

BRITA YTRE ARNE, Post doctor, Department of Information Science and Media Studies, University of Bergen, brita.ytre-arne@uib.no 